\title{
Theatre and Money Introduction
}

\section{LAURA GRÖNDAHL \& S.E.WILMER}

The Association of Nordic Theatre Scholars has increased its activity remarkably during the past year and the journal has gained more visibility since its transition to online open access. In 2017, NTS was selected for inclusion in Web of Science and Scopus as well as Ebsco and Google Scholar. The special number of Nordic Theatre Studies, "Turning Points and Continuity", based on a research project at Stockholm University, was published at the end of December 2017. The conference proceedings of "Theatre and the Popular" came out only two months later in February 2018. Two more issues are already in process: the proceedings of the conference "Rethinking Theatre" arranged by Aarhus University in May 2017, and "Theatre and Continental Philosophy", based on an open call. The fifth annual conference, co-arranged by a Nordic or Baltic university in collaboration with ANTS, took place in Kaunas 26. - 28.4.2018 under the theme "Theatre and Memory Wars".

The association has even more ambitious visions for the future. Discussions are on-going about how it could take a more active role in facilitating scholarly networking and research collaboration between Nordic and Baltic countries. The intention is to develop websites into a joint platform for sharing information and mapping the situation of theatre and performance studies at the universities in the region. The older back issues, which are available only in printed form, need to be digitalized as soon as possible. Yet, all these efforts depend on funding, which has become increasingly hard to gain as the current systems of assessment are often unfavourable for small disciplines 
in the humanities. The theme of the issue at hand, "Theatre and Money", has an ironic undertone since austerity policies have hit the journal as well as theatres, universities, and all cultural activities.

Any form of theatre, art or research has, of course, never been free from economic conditions, be it a matter of ticket sale, governmental funding or the benevolence of private patrons. On the practical level, a temporary shortage of money can often be overcome by creative artists who are good at finding inventive survival strategies during hard times. However, the relations between cultural and economic spheres are being drastically redefined in contemporary society. While monetary issues have previously been considered as incommensurable with art and science, the late capitalist economy merges them together and no life sphere can escape its marketing logic. On the one hand, cultural activities are harnessed to the service of non-artistic purposes like health care, social work and wellbeing, or business training. On the other hand, the public financing of art or science is being cut down; profit-making is requested in every field of cultural activity and artists are urged to become private entrepreneurs.

The recent development seems contradictory to the tradition and values of the Nordic welfare state, and also to the romanticized image of the devoted artist, whose ingenuity cannot be influenced by money and other mundane affairs. Artistic notions like Grotowski's "poor theatre" even indicate that materialistic austerity correlates with spirituality and good aesthetic quality. From today's neoliberal perspective, the romantic idea of a free artist can, however, also be taken as a model for an innovative business man who is independent of all institutional bonds and bureaucratic rules, whose success follows from his/her individual talent, and who is willing to take risks and does not count on governmental subsidies or strive for economic safety. It is not uncommon that artists are, nowadays, recruited to teach creative thinking to business managers.

Business life can certainly benefit from arts in many ways, but their relationship is not always benevolent the other way around. One of the most alarming features in today's society is the tendency to assess all human activities in calculable measurements and economic terms. Art institutions are not only suffering from a lack of money; they are also subordinated to ideologies that dismiss their qualitative and experiential dimensions. It was thus no surprise that the call for articles was responded to by authors concerned about the new conditions of theatre making and the precarious position of contemporary artists.

The article by Cecilie Schmidt presents a case study of the German performance art collective cobratheater.cobra who criticize the structural precarity of freelance work through its activity. Leaning on Lauren Berlant's and Judith Butler's theories, Schmidt asks how the constitutive norms and habits of an organizational infrastructure can be exposed, challenged, and reformed by performative acts. The members of cobratheater.cobra, among other things, reject the idea of individual authorship and signature by "infecting" their artis- 
tic practice, and demonstrate against neoliberalist conditions by disobeying the directives about unemployment benefit.

The financial situation of Estonian theatre is the subject of no less than three articles. Ott Karulin examines Estonian state-owned or statutory funded theatres as natural monopolies, i.e. companies that rule the markets by possessing the majority of resources in a field. He discusses their influence on cultural democracy after the economic crisis of 2008-10 and asks how alternative infrastructures have been created to support other, non-governmental theatres. Madli Pesti and Kristiina Reidolv focus on institutional and artistic changes in post-Soviet Estonian theatre history, taking a closer look at the foundation Vaba Lava established in 2010 to provide opportunities and venues for theatre companies. Pesti and Reidolv suggest that Vaba Lava can respond to social changes and new demands more flexibly than the previous theatre structures because of a more versatile financing system. Heili Einasto and Evelin Lagle research the impact of available venues and rehearsal rooms on the development of dance performances. After giving an informative overview of Estonian dance history in the 20th century, they show how the lack of appropriate spaces has influenced the artistic style and quality of contemporary productions, analyzing the development in terms of "path dependence" i.e. the difficulty of changing the consequences of earlier decisions and financial investments.

As Jurgita Staniškytè points out in her article on the "consumer-friendly" theatre culture, audience participation and interactive performances are twofold phenomena that may promote social engagement as well as adjust artistic activities to capitalist conditions and offer illusory spectacles of democracy. Staniskyte discusses audience development in Lithuanian theatre based on extensive interviews with managers, artistic directors, and audience groups carried out in 2013-14. Although all the examined theatres had educational activities and recognized the need for attracting new audiences, their resources proved to be limited, and they did not have enough understanding about the segmentation and heterogeneity of their audiences.

The working conditions of Finnish theatre are examined in two articles shedding light on both established institutions and smaller, independent groups. Marjatta Häti-Korkeila and Laura Gröndahl focus on the development of the employment policy in large and medium-size city theatres that are subsidized by law. Gathering data from statistics, trade journals, and interviews, they ask how the transition from fixed positions to freelance relationships has influenced the artistic ensemble, the planning of repertoires, and theatre management from the 1990s to 2015. Laura Pekkala and Riku Roihankorpi present a research project Visio, which has investigated the organizational practices of four independent theatres outside of the statutory funding system in 2015-16. The theatres' activities and structures were mapped and analyzed through interviews and observation. Individually tailored development strategies were generated for each theatre based on the results, and their implementation was followed and evaluated. 
Wealth and property are intriguing topics in many classic and popular plays. Teemu Paavolainen analyses money as a function of exchange and ensuing distance in two performances based on well-known extensive television productions, The Age of Iron and Fanny and Alexander. He not only discusses the conflict between richness and poverty as an elementary dramaturgical theme in both stories, but also as two modes of using the stage and theatrical machinery in comparison to the cinematic counterparts of the plays.

The link between theatricality and money also reaches beyond the framework of artistic institutions. Janne Tapper's article examines the significance of artistic performances in the successful story of the Finnish fashion design company Marimekko, founded and mainly led by Armi Ratia from the 1950s to the late 1970s. Tapper proposes a theoretical framework that is built on Josette Feral's concept of the cleft, which frames deviations of quotidian reality as theatrical events. He contextualizes Marimekko with the earlier design tradition developed in the Bauhaus School in the 1920-30s; and compares it to the 2000's model of arts-in-business that engages artists without giving them a leading visionary role like Ratia's.

The open section of this issue includes only one article by Avra Sidiropoulou who compares Henrik Ibsen and Jon Fosse as playwrights using the Nordic landscape and the open sea as metaphoric representations of the protagonists' states of mind. As a theatre director, she benefits from her artistic practice through her staging of Fosse's Someone is Going to Come in 2013 and having undertaken a close reading of Ibsen's The Lady from the Sea. 